\title{
EDITORIALS
}

\section{Setting the Stage: Research to Inform Interventions, Practice and Policy to Improve Women Veterans' Health and Health Care}

\author{
Lori A. Bastian, MD, MPH', Hayden B. Bosworth, $P h D^{2}$, Donna L. Washington, $M D, M P H^{3}$, and \\ Elizabeth M. Yano, $\mathrm{PhD}, \mathrm{MSPH}^{4}$ \\ 'VA Connecticut Healthcare System, University of Connecticut Health Center, Newington, CT, USA; ${ }^{2}$ Durham VA Medical Center, Duke University, \\ Durham, NC, USA; ${ }^{V}$ VA Greater Los Angeles Healthcare System, UCLA School of Medicine, Los Angeles, CA, USA; ${ }^{4}$ VA Greater Los Angeles Healthcare \\ System, UCLA School of Public Health, Los Angeles, CA, USA.
}

J Gen Intern Med 28(Suppl 2):S491-4

DOI: $10.1007 / \mathrm{s} 11606-013-2470-9$

(c) Society of General Internal Medicine 2013

$\mathrm{W}$ ith increasing participation of women in the U.S. military, and more than 2.2 million U.S. women Veterans, the health and health care of military and Veteran women is an important Veterans Health Administration (VA) priority. The goal of this supplement is to disseminate new research findings; highlight research that can lead to improvements in care; and raise awareness of, stimulate interest in, and increase research about the health care of women Veterans and women in the military. The supplement was sponsored by the VA Health Services Research \& Development Service (HSR\&D) through the VA Women's Health Research Consortium. Two previous supplements/ special theme issues published in 2006 and 2011 focused on women Veterans' research. We received a record number of manuscripts for this third and updated supplement (79) and we ultimately accepted 19 manuscripts. The quality of the research was outstanding. To adhere to publishing constraints, 16 manuscripts appear in this supplement, with the other three manuscripts being published in a regular issue of JGIM.

This supplement addresses many women's health issues that are emerging areas for the care of women Veterans. The research published herein will inform the care of women Veterans by general internists within and outside of the VA. We have organized the supplement based on six main topics identified in the 2010 VA agenda setting conference for women's health research led by Yano et al. (2011). ${ }^{1}$

\section{ACCESS TO CARE AND RURAL HEALTH}

Prior research has characterized barriers to accessing VA care, but there has been little attention to why women chose to use VA services. Hamilton et al. have completed an exploration of why women Veterans leave the VA, as an opportunity to better understand patients' perceptions of the care they received. ${ }^{2}$ They used the National Survey of Women Veterans, a 2008-2009 survey of 3,611 women Veterans that was the first population-based nationally representative study of women Veterans' health care needs and use in over 25 years. Over time, $54 \%$ of VA users reported that they no longer use the VA for healthcare services. Understanding reasons for discontinuing VA use can help target improvements in care delivered. A newly VA-funded Collaborative Research to Enhance \& Advance Transformation \& Excellence (CREATE) study, "Lost to Care: Attrition of Women Veterans New to VHA," is expected to inform efforts to sustain women Veterans' enrollment in, and continued use of, VA care for which they are eligible. (PIs: Susan Frayne, M.D., M.P.H. and Alison Hamilton, Ph.D., M.P.H.) The project will examine patient, provider and organizational factors that influence why women Veterans leave VA care.

\section{PRIMARY CARE AND PREVENTION}

Articles in this supplement identify the most common risk factors for cardiovascular disease among women in middle adulthood (aged 35-64 years). In particular, Vimalananda et al. report results of a cross-sectional study from the Diabetes Epidemiologic Cohorts, a national longitudinal data set of patients in the VA system. ${ }^{3}$

In this study, veterans have high rates of cardiovascular disease (CVD) risk factors. While men have a higher prevalence of hypertension, hyperlipidemia, and diabetes, the gap in overall risk factor burden narrows with increasing age. Over one-third of women Veterans in VA have more than two CVD risk factors at age 55-64 years. Interventions to reduce CVD risk among veterans should be designed with both women and men in mind. Rose et al. go further to explore racial and ethnic differences in these risk factors in the 2008-2009 National Survey of Women Veterans. ${ }^{4}$ Among women Veteran respondents, racial/ethnic differ- 
ences in cardiovascular risk factors persisted after adjusting for age. Black women were more likely to be obese and report hypertension and diabetes, but less likely to report smoking cigarettes compared to non-Hispanic white women. Hispanic women were more likely to report diabetes and smoking, but less likely to report hypertension compared to non-Hispanic women. Further, in a retrospective cohort of Veterans aged 50-75 with diabetes, Vimalananda and her colleagues also explored gender differences in lipid management. $^{5}$ Among the highest-risk group (those with ischemic heart disease), gender differences are present and increase with age. To reduce these persistent disparities, we need interventions that target risk factor reduction in highrisk groups, accounting for cultural and contextual factors that may underlie these disparities.

\section{MENTAL HEALTH}

Historically, women's mental health research represented a major proportion of VA women's health research. Pavao et al. examined a large cohort $(126,598)$ of homeless Veterans for rates of military sexual trauma. ${ }^{6}$ Approximately $40 \%$ of women and $3 \%$ of men experienced military sexual trauma. Those Veterans who had experienced trauma had increased odds of having one or more mental health conditions. ${ }^{6}$ Homeless women Veterans may specifically need treatment programs that address the combination of trauma exposure and other mental health conditions. Given the overrepresentation of Veterans among the homeless, these findings may inform treatment approaches that address Veterans' traumatic exposures and mental healthcare needs.

A high percentage of Veterans seeking care in VA Medical Centers have post-traumatic stress disorder (PTSD). Bernardy et al. examined pharmacy records to describe prescription patterns for men and women Veterans with PTSD from 1999 to 2009. ${ }^{7}$ Women Veterans were more likely to receive medications for PTSD compared to men, except for prazosin, which was prescribed more frequently in men. The most concerning gender discrepancy was observed for benzodiazepines where prescriptions have decreased for men and steadily increased for women Veterans, despite guideline recommendations against their use for PTSD. It is important to monitor quality of care and to assess for appropriate adherence to evidence-based clinical practice guidelines.

\section{HEALTH CONCERNS ASSOCIATED WITH MILITARY DEPLOYMENT}

Yan et al. report on the types of stressors women Veterans report before and after deployment. ${ }^{8}$ Among 79 National
Guard and Reserve women deployed to Operation Enduring Freedom (OEF) and Operation Iraqi Freedom (OIF), interpersonal issues (namely family and friend issues and concerns) were the most common type of stressors. Women Veterans need more services in the community to address their post-deployment issues. Using a national mail survey of 2,344 OEF/OIF Veterans, Street et al. examined gender differences in mental health conditions and deployment stressors. ${ }^{9}$ Women Veterans were more likely to report exposure to sexual harassment, but less likely to report exposure to combat compared to men. Women and men were also equally likely to report symptoms consistent with PTSD and women were more likely to report clinically important depressive symptoms and less likely to report problematic alcohol use. Maguen et al. explored body mass index (BMI) trends in a cohort of OEF/OIF Veterans. ${ }^{10}$ They identified high rates $(75 \%)$ of overweight and obesity in this relatively young group of Veterans. Among women, obesity rates were highest among those with depression. Interventions are needed to reduce these trends in obesity and a focus on including depressive symptom treatment may increase their effectiveness.

\section{COMPLEX CHRONIC CONDITIONS/AGING AND LONG-TERM CARE}

VA research on women Veterans' complex chronic care needs has been limited at best. In this Supplement, Washington et al. identified population profiles that highlight differences in women Veterans' health and healthcare use by period of military service. ${ }^{11}$ Differences were present in the types and amount of healthcare used. Despite their younger age, OEF/OIF women Veterans had the greatest number of healthcare visits. Higher rates of mental health disorders among OEF/OIF women Veterans reinforces the need for co-located primary and mental health care for women. Blackstock et al. examined whether sex differences exist in disease burden in a cohort of HIV-infected Veterans after 1 year of antiretroviral therapy (ART). ${ }^{12}$ Among 227 women and 8,073 men, Veteran Aging Cohort Study index scores (a measure of overall disease burden) improved after ART, but women experienced less improvement. Future research is needed to understand this disparity in HIV burden and reduce chronic disease burden for women Veterans.

\section{REPRODUCTIVE HEALTH}

Several papers describe the current infrastructure and availability of reproductive services in VA hospitals and clinics. Cordasco et al. examined resources and processes in 
place for evaluating and treating gynecologic and obstetric conditions and sexual assault in all 120 VA emergency departments. ${ }^{13}$ Gaps in availability of reproductive services were identified and potential solutions discussed. Katon et al. utilized a 2007 national census of 193 VA sites to evaluate the on-site availability of contraceptive technology (i.e., IUD placement), prenatal care, and infertility evaluation and treatment stratified by hospital-based versus community-based clinical setting. ${ }^{14}$ Fewer specialized reproductive services were available in the VA communitybased outpatient clinics, suggesting there is an opportunity to expand services for women who seek care in these clinical settings.

Another important paper addresses reproductive issues that general internists need to be aware of when prescribing medications to women. Schwartz et al. conducted a crosssectional survey of $286 \mathrm{OEF} / \mathrm{OIF}$ Veterans, examining receipt of counseling when medicines that can cause birth defects are prescribed. ${ }^{15}$ These investigators found that awareness of the need for preconception counseling among VA providers is needed.

A particular concern is also whether lesbian and bisexual (LB) women Veterans are accessing VA services and if the system is ready and able to provide highquality and sensitive care, now that Public Law 103-160, otherwise known as "Don't Ask, Don't Tell", has been reversed. Due to previous policies and stigma associated with LB identity, little research has been conducted in this area, particularly among women Veterans. Two manuscripts in this Supplement address the importance of research among LB women and report that significant barriers to accessing care may exist. Drs. Lehavot and Simpson provide their perspective on how this important topic can be better examined in research studies. ${ }^{16}$ Mattocks et al. conducted a cross-sectional study of OEF and OIF women Veterans at two VA facilities, asking also about sexual preference. ${ }^{17}$ LB women reported more sexual victimization both within the military and as children compared to heterosexual women. These papers suggest that cultural competency trainings are needed within the VA to improve care for this population.

\section{EDITORIALS: THE CONTEXT FOR VA WOMEN'S HEALTH RESEARCH}

Dr. Atkins, Director of the VA HSR\&D Service, highlights the research that HSR\&D has supported and funded to increase of women Veterans health and gender differences in health and health care. Dr. Frayne, Director of the new VA Women's Health Practice-based Research Network (PBRN), highlights features of the PBRN and its role in advancing VA capacity to increase women Veterans' voice in VA research and to improve women Veterans' care. Dr. Hayes, Chief Consultant of VA Women's Health Services (WHS), describes current WHS initiatives, research-clinical partnerships, and what she thinks the future portends. Dr. Clancy, MD, Director of the Agency for Healthcare Research and Quality, provides further national context (non-VA) for VA's efforts in women's health during health care transformation.

\section{FUTURE DIRECTIONS}

Next steps to improve the health and healthcare of women Veterans should include supporting more interventions and implementation research. The VA Women's Health PBRN provides the VA facility partnership needed to help VA researchers and clinicians to accomplish this goal, while the VA Women's Health Research Consortium supports needed training, mentorship, technical consultation and dissemination support. Recently, the VA HSR\&D funded the Women's Health CREATE, which is a group of five projects that collectively aim to accelerate implementation of comprehensive women's health care within VA. This group of researchers is well positioned to address the research agenda in partnership with VA Women's Health Services and the over $200 \mathrm{VA}$ investigators committed to achieving the agenda's goals. The women who serve our country deserve nothing less than our total commitment to improve their health and health care.

Disclosures: This material is based upon work supported by the Department of Veterans Affairs, Veterans Health Administration, Office of Research and Development, and Health Services Research and Development SDR-10-012.

Disclaimer: The views expressed in this editorial are those of the authors and do not necessarily reflect the position or policy of the Department of Veterans Affairs or the United States government.

Conflict of Interest: The authors declare that they do not have a conflict of interest.

Corresponding Author: Lori A. Bastian, MD, MPH; VA Connecticut Healthcare System, University of Connecticut Health Center, 555 Willard Avenue, Newington, CT 06011, USA (e-mail: Lori.bastian@va.gov).

\section{REFERENCES}

1. Yano EM, Bastian LA, Bean-Mayberry B, Eisen S, Frayne S, Hayes P, et al. Using research to transform care for women veterans: advancing the research agenda and enhancing research-clinical partnerships. Women's Health Issues. 2011;21(4 Suppl):S73-83.

2. Hamilton AB, Frayne SM, Cordasco KM, Washington DL. Factors related to attrition from VA Healthcare use: findings from the National Survey of Women veterans. J Gen Intern Med. 2013. doi:10.1007/ s11606-013-2347-y. 
3. Vimalananda VG, Miller DR, Christiansen CL, Wang W, Tremblay P, Fincke BG. Cardiovascular disease risk factors among women veterans at VA medical facilities. J Gen Intern Med. 2013. doi:10.1007/s11606-013-2381-9.

4. Rose DE, Farmer M, Yano EM, Washington DL. Racial-ethnic differences in cardiovascular risk factors among women veterans. J Gen Intern Med. 2013. doi:10.1007/s11606-012-2309-9.

5. Vimalananda VG, Miller DR, Hofer TP, Holleman RG, Klamerus ML, Kerr EA. Accounting for clinical action reduces estimates of gender disparities in lipid management for diabetic veterans. J Gen Intern Med. 2013. doi:10.1007/s11606-013-2340-5.

6. Pavao J, Turchik JA, Hyun JK, Karpenko J, Saweikis M, McCutcheon S, Kane V, Kimmerling R. Military sexual trauma among homeless veterans. J Gen Intern Med. 2013. doi:10.1007/s11606-013-2341-4.

7. Bernardy NC, Lund BC, Alexander B, Jenkyn AB, Schnurr PP Friedman MJ. Gender differences in prescribing among veterans diagnosed with post-traumatic stress disorder. J Gen Intern Med. 2013. doi:10.1007/s11606-012-2260-9.

8. Yan GW, McAndrew L, D'Andrea EA, Lange G, Santos SL, Engel CE, Quigley KS. Self-reported stressors of National Guard women Veterans before and after deployment: the relevance of interpersonal relationships. J Gen Intern Med. 2013. doi:10.1007/s11606-012-2247-6.

9. Street AE, Jaimie L, Gradus JL, Hannah L, Giasson HL, Vogt D, Resick PA. Gender differences among veterans deployed in support of the Wars in Afghanistan and Iraq. J Gen Intern Med. 2013. doi:10.1007/ s11606-013-2333-4.

10. Maguen S, Madden E, Cohen B, Bertenthal D, Neylan T, Talbot $\mathbf{L}$, Grunfeld C, Seal K. The Relationship between Body Mass Index and Mental Health among Iraq and Afghanistan Veterans. J Gen Intern Med. 2013. doi:10.1007/s11606-013-2374-8.
11. Washington DL, Bean-Mayberry B, Hamilton AB, Cordasco KM, Yano EM. Health Profiles of U.S. Women Veterans by War Cohort: findings from the National Survey of Women Veterans. J Gen Intern Med. 2013. doi: 10.1007/s11606-012-2323-y.

12. Blackstock OJ, Tate JP, Akgün KM, Crystal S, Duggal M, Edelman EJ, Kirsha S, Gordon KS, Rimland D, Wang EA, Fiellin DA, Justice AC. Are there sex differences in overall burden of disease among HIVinfected Individuals in the Veterans Affairs healthcare system? J Gen Intern Med. 2013. doi:10.1007/s11606-013-2346-z.

13. Cordasco KM, Zephyrin LC, Kessler CS, Mallard M, Canelo I, Rubenstein LV, Yano EM. An inventory of VHA emergency departments' resources and processes for caring for women. J Gen Intern Med. 2013. doi:10.1007/s11606-012-2327-7.

14. Katon J, Reiber G, Rose D, Bean-Mayberry B, Zephyrin L, Washington DL, Yano EM. VA location and structural factors associated with on-site availability of reproductive health services. J Gen Intern Med. 2013. doi: $10.1007 /$ s11606-012-2289-9.

15. Schwarz EB, Mattocks K, Brandt C, Borrero S, Zephyrin LC, Bathulapalli H, Haskell S. Counseling of female Veterans about risks of medication-induced birth defects. J Gen Intern Med. 2013. doi: $10.1007 / \mathrm{s} 11606-012-2240-0$.

16. Levahot $\mathbf{K}$, Simpson TL. Incorporating lesbian and bisexual women into women veterans' health priorities. J Gen Intern Med. 2013. doi:10.1007/ s11606-012-2291-2.

17. Mattocks KM, Sadler S, Yano EM, Krebs EE, Zephyrin L, Brandt C, Kimerling R, Sandfort T, Dichter ME, Weiss JJ, Allison J, Haskell S. Sexual victimization, health status, and VA healthcare utilization among lesbian and bisexual OEF/OIF veterans. J Gen Intern Med. 2013. doi: $10.1007 / \mathrm{s} 11606-013-2357-9$. 